\title{
O CANAL DE MARKETING CONFIGURADO PELAS CENTRAIS DE COMPRA
}

Aline Lourenço de Oliveira ${ }^{1}$ Cleber Carvalho de Castro ${ }^{2}$

RESUMO

O setor varejista tem constituído Centrais de Compras (CCs) com a intenção de conseguirem melhores condições de negociação. Este é um formato associativista, que busca se posicionar no canal de marketing entre os varejistas e os atacadistas ou fabricantes. Criadas com o objetivo de aumentar a competitividade das empresas parceiras, as $\mathrm{CC}$ s proporcionam aos varejistas representatividade no canal de marketing frente aos demais agentes. Dessa forma, o pressuposto deste estudo é que as CCs estão promovendo mudanças nos relacionamentos dos agentes que integram o canal de marketing. Por meio de uma revisão bibliográfica, este trabalho busca refletir sobre a presença das CCs no canal de marketing, identificadas como um novo agente que passa a integrar e influenciar sua atuação.

Palavras-Chave: Canal de Marketing. Varejo. Central de Compra.

\section{$* * *$}

1. Doutora, e-mail: aoliveirah@gmail. com

2. Doutor, e-mail: clebercastrouai@ gmail.com $* * *$ 
$O$ varejo representa um importante agente no canal de marketing. Pela sua proximidade com o consumidor, detém informações privilegiadas em relação as suas necessidades e seus desejos, suas opiniões sobre produtos e preços e sobre os comportamentos de compra. Uma importante função desempenhada pelovarejo,em especialo de pequeno porte, é a de colocar bens e serviços disponíveis nos lugares mais diversos, tornando produtos e marcas conhecidas de um grande público consumidor.

\section{O setor varejista vivencia uma acirrada} concorrência, não só em relação ao elevado número de pontos de vendas, mas principalmente devido às grandes redes, nacionais e internacionais, que fazem um movimento de expansão de sua área de atuação chegando às mais diversas regiões do país.

Essa conjuntura dificulta as atividades do pequeno varejo, cujos problemas enfrentados no Brasil são notórios. Segundo pesquisa realizada pela Vox Populi (2005), do universo de micro e pequenas empresas pesquisadas, $49,5 \%$ das extintas pertenciam ao comércio. A taxa de mortalidade é um dado interessante, que chama a atenção para a dificuldade que essas empresas encontram para manter-se no mercado.

Neste contexto, os formatos associativistas têm ganhado força entre pequenas empresas do setor de comércio, como estratégias de enfrentamento às ameaças do ambiente organizacional. As Centrais de Compras (CCs) se destacam como uma alternativa por possibilitarem compras em escala, por meio da negociação de mix de produtos de interesse comum dos associados, adquirindo volume, variedade e valor que um pequeno varejista individualmente não conseguiria atingir.

Com essa estratégia, obtêm-se condições de negociação, com melhores preços, prazos de pagamento e de entrega. Essas condições geram não só redução dos preços no ponto de venda, mas o aumento do mix de produtos vendidos, reposição rápida dos estoques e possibilidade de financiamento dos clientes.

Dessa forma, a CC passa a ocupar uma importante posição no canal de marketing, posicionada entre os varejistas e os atacadistas e fabricantes, o que provoca mudanças na estrutura convencional. Assim, os pequenos varejistas passam a ter representatividade e condições de pressionar os demais agentes a favor de seus interesses.

Neste artigo, faz-se uma revisão bibliográfica sobre a configuração do canal de marketing mediante a presença das $\mathrm{CC}$, que agem intermediando os varejistas frente aos distribuidores e fabricantes. Admitindo-se que a CC é um agente cada vez mais presente, atuante e instigador de mudanças de comportamentos, papéis e responsabilidades, este trabalho busca contribuir com os estudos sobre o canal de marketing e o comportamento do pequeno varejo.

Este estudo está estruturado em cinco partes, tendo início nesta introdução. A segunda seção apresenta o conceito de canal de marketing e aborda as relações interorganizacionais que o caracterizam. A terceira enfatiza as CCs como uma estratégia utilizada pelo varejo para enfrentar as adversidades do mercado. No quarto tópico, são feitas reflexões sobre a atuação da CC no canal de marketing. Encerra-se com algumas considerações que sintetizam e apontam a ideia central do trabalho. 


\section{CANAL DE MARKETING}

Segundo Berman (1996), canais de marketing correspondem a uma rede organizada de agências einstituições combinadas, que desempenham as atividades mercadológicas necessárias para ligar produtores a usuários. Kotler e Keller (2012) e Coughlan et al. (2012) o conceituam como um conjunto de organizações independentes envolvidas no processo de disponibilizar um produto ou serviço para uso ou consumo.Assim, pode-se dizer que o canal de marketing é um caminho ordenado de agentes interconectados que criam valor para os usuários finais e é composto normalmente por fabricantes, intermediários (atacadistas, varejistas, especialistas) e usuários finais (consumidores industriais ou domésticos), sendo que o número de agentes varia conforme as particularidades de produtose demandas,estando sempre presentes fabricante e consumidor.

Em relação a sua extensão, o que vai determinar é a quantidade de intermediários que o integram (KOTLER; KELLER, 2012). Dessa forma, um canal de marketing de nível "zero", também chamado de direto, corresponde à ligação entre fabricante e usuário final, como ocorrem nas vendas por catálogo, por mala-direta, televisão e internet. No nível "um", há apenas um intermediário (relação fabricante-varejista - consumidor final), bem como nos dois níveis há dois intermediários (atacadista e varejista), e assim sucessivamente como ilustrado pela figura 1 .

Figura 1: Caminho que o produto percorre até o consumidor
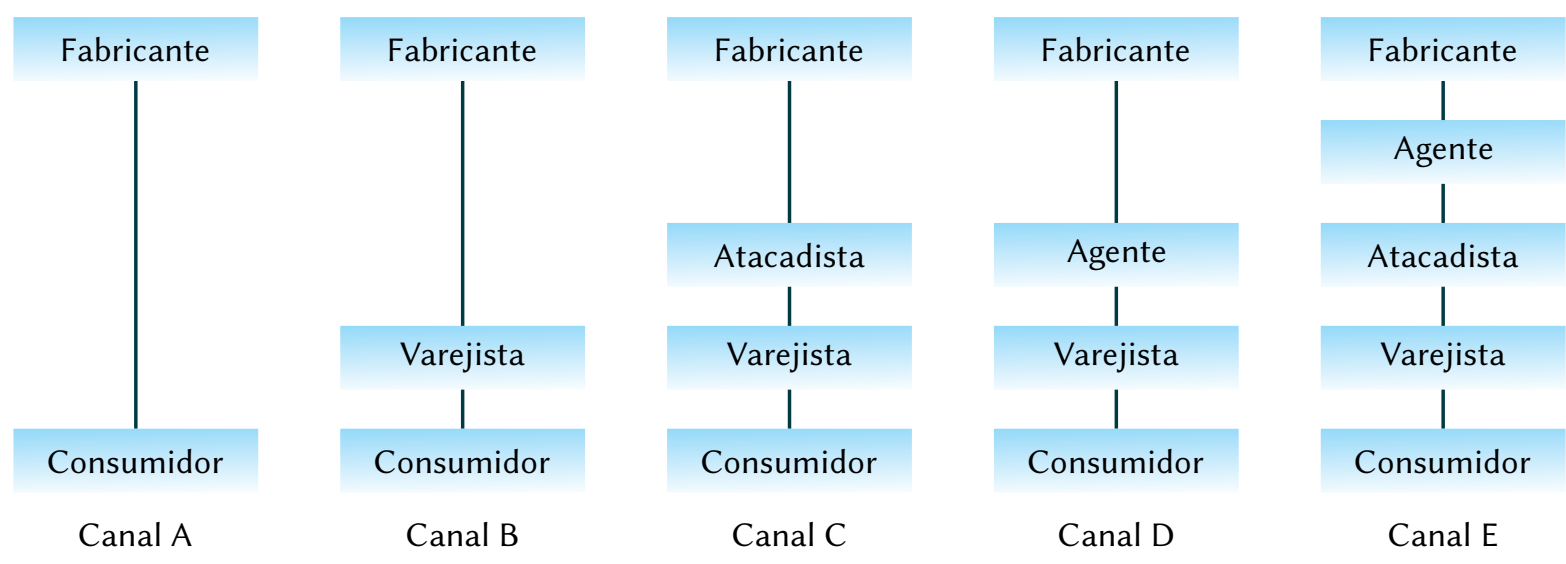

Fonte: Rosenbloom (2001)

A essência do canal de marketing encontra-se em tornar disponíveis bens e serviços para o maior número de consumidores. Sua estrutura busca atender aos fabricantes que precisam distribuir sua produção ao menor custo possível. Dessa necessidade, surge a figura do intermediário que, genericamente, são os agentes que não se classificam como fabricante ou usuário final. Nesta categoria é possível ter: atacadistas; varejistas e agentes ou especialistas, que são organizações que realizam atividades específicas de apoio ao canal de marketing. (COUGHLAN et al., 2012; KOTLER; KELLER, 2012). 
O canal de marketing possibilita o aumento da eficiência do processo de levar bens e serviços de produtores a consumidores. Para a demanda é importante, pois facilita a busca nas suas extremidades e promove o ajuste da discrepância de sortimento. Facilitar a busca refere-se a colocar em contato o fabricante, que não sabe como alcançar o consumidor final e este, por sua vez, que desconhece onde encontrar os produtos de que necessita (COUGHLAN et al., 2012). Assim, por meio do intermediário, pode-se localizar o fabricante que produz obem ou serviço desejado pelos consumidores, ou no movimento contrário, quando é o fabricante que não sabe como chegar a um consumidor específico, utiliza-se dos intermediários para entrar em contato com ele.

O ajuste da discrepância de sortimento consiste em equilibrar a diversidade do que é produzido com a necessidade de consumo. A discrepância ocorre devido ao fato de os fabricantes, em geral, produzirem uma grande quantidade de um provimento limitado de bens, enquanto os consumidores normalmente demandam apenas uma quantidade limitada de um grande sortimento de bens e mercadorias. (COUGHLAN et al., 2012).

Em relação a quem está ofertando, o canal interfere na eficiência por meio das rotinas de transação e da redução do número de contatos. As rotinas de transação estabelecem certa frequência das operações de pedir, avaliar e pagar por bens e serviços (COUGHLAN et al., 2012), o que regula as atividades dos agentes de produzir e estocar conforme a demanda, o ciclo de pedidos e o ciclo financeiro. As rotinas de transação permitem que o produto acabado saia do estoque, transforme-se em dinheiro e retorne ao caixa gerando mais insumos e novos produtos dentro de uma estimativa de prazos e quantidades.
A redução do número de contatos refere-se à possibilidade de negociar com um número menor de intermediários sem perder a amplitude de distribuição dos produtos (COUGHLAN et al.,2012). A escolha dos atacadistas que têm condições de colocar os produtos nos pontos de varejo mais adequados a sua distribuição, permite que estejam à disposição de um grande número de consumidores potenciais. Essa possibilidade diminui o número de transações e, com isso, as incertezas e os riscos são amenizados, do mesmo modo que se expandem as condições de retorno financeiro.

Para os clientes, o canal de marketing é positivo ao permitir que bens e serviços específicos cheguem a eles por meio da geração de utilidade de lugar, tempo e posse (ROSENBLOOM, 2001; LAS CASAS, 2006). A utilidade de lugar refere-se à possibilidade de comprar produtos em locais convenientes ao consumidor no momento necessário e no tempo certo. A utilidade de posse dos produtos é definida nas negociações de venda realizadas nos pontos comerciais, possibilitando, assim, que produtos passem a pertencer ao consumidor.

Projetar um canal de marketing requer que sejam analisadas as necessidades do cliente, que se estabeleçam os objetivos, identifique e avalie as principais alternativas (OLIVEIRA; OLIVEIRA, 2005). Segundo Kotler e Keller (2012) e Iacobucci (2001), após definir seu mercado-alvo e o posicionamento desejado, uma empresa deve identificar suas opções de canal de marketing, que é descrita por três elementos: os tipos de intermediários disponíveis, o número de intermediários necessários e as condições de responsabilidade de cada membro.

Pigatto (2006) destaca que os papéis e as responsabilidades dos membros do canal mudaram em comparação ao que era habitual. 
As atividades de produzir, comprar, vender e entregar não são mais suficientes para garantir obom desempenho, sendo necessário desenvolver a responsabilidade em desempenhar com excelência a atividade central de se relacionar e trabalhar cooperativamente.

O relacionamento entre as empresas que compõem um canal de marketing é consequência de dois fatores antagônicos. O primeiro é o conflito, que representa divergências presentes na relação comercial e o segundo é a dependência mútua, que mostra que sem parceria nenhuma organização pode atender de maneira eficiente às necessidades do consumidor. (PIGATTO, 2006; CASTRO; LADEIRA, 2012).

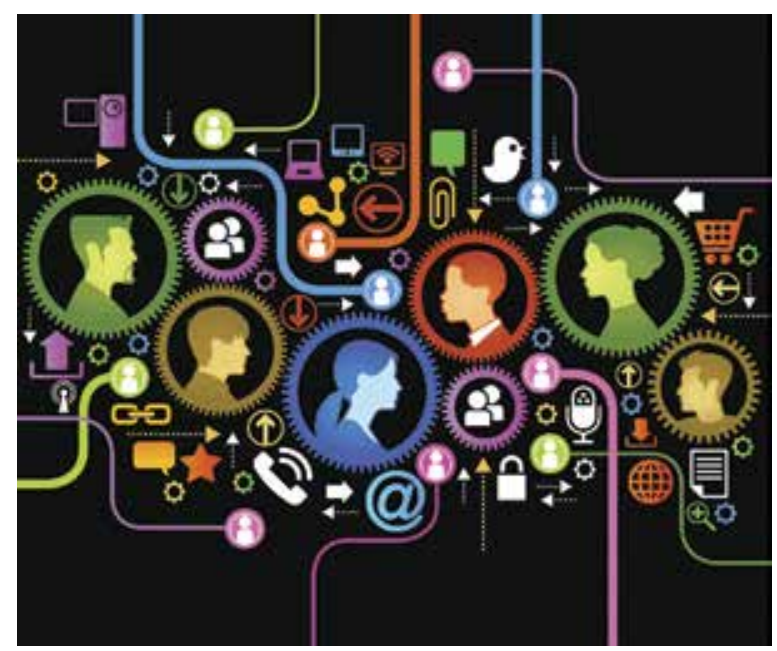

O CANAL DE MARKETING SE MOVIMENTA EM TORNO DO PROPÓSITO DE COLOCAR PRODUTOS À DISPOSIÇÃO DOS CONSUMIDORES, E ISSO OCORRE PERMEADO PELA COMPETIÇÃO ENTRE OS AGENTES, DE MESMO NÍVEL E DE NÍVEIS DIFERENTES, QUE BUSCAM UM LUGAR DE DESTAQUE NA COMUNICAÇÃO COM O CONSUMIDOR.
Um grande desafio no canal é gerir o comportamento competitivo de forma que traga mais pontos positivos que negativos.

Segundo Las Casas (2006), há dois tipos de conflito em canais de distribuição: os conflitos com empresas do mesmo nível e com empresas de diferentes níveis. Os conflitos de mesmo nível ou horizontal referem-se às desavenças entre fabricantes, entre atacadistas e assim por diante, cujas causas podem ser as mais variadas como, por questões de território, de práticas competitivas, entre outras. Os conflitos de níveis diferentes ou verticais acontecem quando alguma empresa concede privilégios para clientes e os demais agentes entendem que esta ação os prejudica.

Para Coughan et al. (2012), o conflito no canal surge quando um membrovê seu parceiro como adversário. A maioria dos conflitos tem como fonte as diferenças nos (1) objetivos dos membros do canal; (2) na percepção da realidade; (3) na delimitação de áreas de domínio e atuação.

Na visão de Kotler e Keller (2012), a melhor solução para situações de conflito é a cooperação entre os membros do canal. Closs e Bowersox (2004, p. 98) enfatizam que "somente por meio da cooperação no âmbito de todo o canal podem ser plenamente satisfeitas as necessidades logísticas e de marketing para uma distribuição bem-sucedida”. A cooperação gera confiança entre os agentes, o que significa acreditar na integridade do outro e preocupar-se com o bem-estar mútuo (COUGHLAN et al.,2012).

As alianças são construídas com base na confiança que surge mediante relacionamentos intensos entre os agentes. Para que uma aliança ocorra, as necessidades especiais de um lado devem ser supridas de forma adequada pelo outro e a durabilidade desse relacionamento precisa ser importante, de igual forma, para ambas as 
partes. Assim, dois fatores são imprescindíveis para que a confiança ocorra e gere alianças: a comunicação aberta, mútua, frequente e o tempo. Uma estratégia para criar e manter alianças de canal requer persistência, recursos e paciência. (COUGHLAN et al., 2012).
As alianças são estratégias que buscam o fortalecimento dos parceiros por meio da complementariedade de pontos essenciais e do compartilhamento de informações, conhecimentos e riscos. Essa estratégia

possibilita que agentes alcancem objetivos que individualmente não conseguiriam.

As CCs representam um tipo de aliança que tem ocorrido entre varejistas de pequeno porte de forma ascendente.O propósito de estabelecer essa estratégia pode ter diversas razões, mas normalmente se dá pela necessidade de aumentar a competitividade frente aos agentes do mesmo nível e de obter representatividade nocanal.(OLIVEIRA;ANTONIALLI,2007).

\section{CENTRAIS DE COMPRA: UMA ESTRATÉGIA PARA O PEQUENO VAREJO}

Segundo Parente (2000), nenhum outro negócio movimenta atualmente tanto dinheiro como o varejo, a ponto de ser um dos destaques do século XXI, em comparação ao que foi a hegemonia da indústria no século XX. O que lhe tem conferido uma forte ascensão dentro do canal de marketing, forçando a redefinição de papel e de ações, em especial como resposta à intensa concorrência que caracteriza esse setor.

Ao longo dos últimos 40 anos, o setor de varejo no Brasil passou por muitas mudanças, conforme destacado por Parente (2000). Diversos modelos de lojas foram cedendo lugar a formatos mais modernos como, por exemplo, os shoppings centers e as lojas de departamentos, que são mais eficientes e mais adequados às novas exigências do mercado, dos consumidores e do canal de marketing.
Localizados na extremidade do canal, os pequenos varejistas sofrem pressões provenientes dos fabricantes, atacadistas, grandes redes de varejo e do consumidor, que os forçam a se adequar, por exemplo, a preços, a condições de financiamento, à variedade do mix de produtos e à qualidade dos serviços prestados. No entanto, limitações como de recursos financeiros, tecnológicos, de capacitação, de estrutura física dificultam essas empresas a acompanharem o ritmo das exigências.

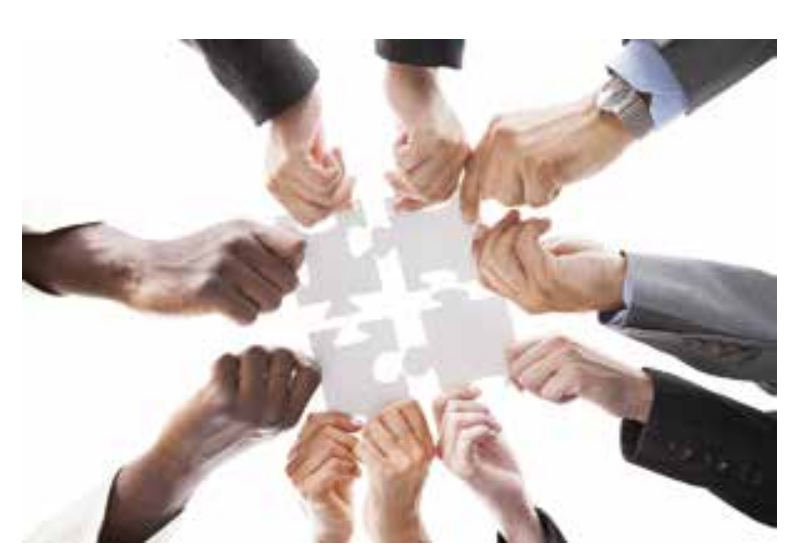




\section{Desta FORMA, AS CCs MOS-}

TRAM SER UMA ALTERNATIVA

INTERESSANTE, POIS REÚNEM

EMPRESAS DE UM MESMO POR-

TE QUE, COMPRANDO JUNTAS,

CONSEGUEM PREÇOS E PRAZOS

DE PAGAMENTO MELHORES,

BEM COMO VARIEDADE E

QUANTIDADE DE PRODUTOS

QUE INDIVIDUALMENTE NÃO

CONSEGUIRIAM.

Através desse intermediário que passa a ser a $\mathrm{CC}$, os parceiros conseguem ocupar um novo status no canal de marketing (Lopes et al.,2005), mantendo-se pequeno, mas adquirindo condições de negociação de empresas maiores.

Segundo Quental et al. (2001), as CCs começaram a ganhar corpo em vários estados brasileiros, dando novo fôlego aos pequenos e médios varejistas que ainda resistem à forte concorrência. Diversos setores como de supermercados, de drogarias e de material de construção têm adotado esse tipo de estratégia. Além da negociação de produtos, as CCs podem ser uma ótima oportunidade para que os envolvidos ampliem os benefícios obtidos pela união com outras empresas. Com as compras

bem assistidas, os parceiros podem buscar melhorias em questões de logística, de divulgação e promoção, de assessoria jurídica, de recrutamento e treinamento dos funcionários, de estrutura física dos pontos de venda, de aquisição e implementação de novas tecnologias, entre outras (QUENTAL et al., 2001; OLIVEIRA; REZENDE; CARVALHO, 2011).

Em relação ao canal de marketing, as CCs passam a realizar a função de "comprador atacadista" para os varejistas que a integram (COUGHLAN etal.,2012; PARENTE,2000; LEWIS, 1968). Essa condição lhes tem conferido crescente poder, que podem ser explicados pelo: a) aumento no porte e poder de compra; b) aplicação de avançadas tecnologias; c) uso de modernos conceitos e técnicas de marketing (ROSENBLOOM,2001).A esses três, pode-se inserir um quarto fator, a maior proximidade com o consumidor final, o que permite às $\mathrm{CCs}$ terem acesso a demandas e desejos do consumidor e repassarem essas informações aos demais agentes que compõem o canal. (PIGATTO, 2006).

Dessa forma, o pressuposto deste estudo é que as centrais de compra estão promovendo mudanças nos relacionamentos dos agentes que integram o canal de marketing, e é sobre isso que este artigo se propõe a refletir. 


\section{CENTRAIS DE COMPRA (CC): UM NOVO AGENTE NO CANAL DE MARKETING}

As CCs estão ocupando uma importante posição no canal de marketing ao alocaremse entre varejistas, atacadistas e fabricantes (figura 2). Elas representam os interesses de vários varejistas simultaneamente.

Figura 2: Inserção das centrais de compras no canal de marketing

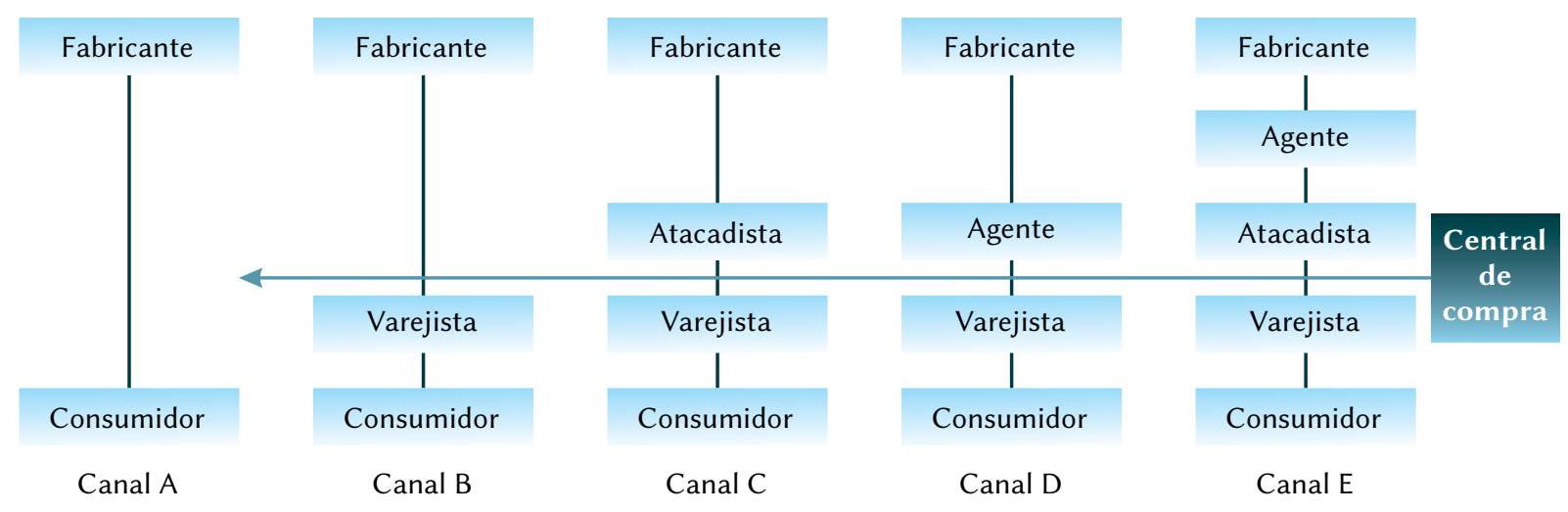

Fonte: Adaptado de Rosenbloom (2001)

Nesta posição, comportam-se como agentes varejistas para os atacadistas e fabricantes ou atacadistas para os varejistas. Com os atacadistas, as CCs negociam produtos com o intuito de venda direta ao consumidor, porém com volume e sortimento maior que um pequeno varejista isoladamente faria. Na sequência, distribuem os produtos conforme acordos preestabelecidos em termos de tipo de produto, marca, quantidade, prazo de entrega e valor da compra.

Para o atacadista, negociar com a CC é interessante, visto que: a) possibilita vendas maiores, em quantidade evalor concentrados em um único agente; b) mais facilidade de negociação, uma vez que os pequenos varejistas normalmente não possuem uma pessoa exclusiva para o setor de compras; c) com um único contato é possível disseminar informações de interesse para vários varejistas; d) reduz o risco de inadimplência, pois concentra a negociação em um agente que tem interesse em manter a imagem positiva para não prejudicar sua atuação no mercado.

Todavia, as CCs também podem ser encaradas como um problema, pois, como o poder de barganha é maior, as exigências na negociação de preços de produtos, prazo de pagamento e de entrega também aumentam. Se o fornecedor atacadista não souber trabalhar com essa nova realidade, ele pode tentar boicotá-la incentivando o varejista a realizar compras individuais. Caso o parceiro não esteja suficientemente comprometido com a $\mathrm{CC}$, pode agir de forma oportunista, enfraquecendo a aliança.

Dependendo do poder de compra que uma CC possui, ela pode tentar negociar diretamente com fornecedores, eliminando a intermediação de atacadistas, o que não é bem visto pelos 
agentes atacadistas, pois representa a perda de clientes, queda nas vendas e em incentivos por parte dos fabricantes. Contudo, para o fabricante, eliminar o atacadista pode ser interessante, uma vez que encurta a comunicação com o varejista e,com isso, consegue obter informações mais rápidas sobre o consumidor. A transação de compra e venda também pode ser mais favorável para as partes ao eliminar um nível do canal de marketing. As CCs representam um novo mercado a ser explorado pela indústria, que necessita de políticas de desenvolvimento próprias.

Ressalta-se, ainda, que a CC não elimina as negociações individuais das empresas parceiras, pois, normalmente, ela se ocupa da aquisição de um mix limitado de produtos de interesse comum dessas empresas. Ocorre que cada parceiro compõe o sortimento de produtos de seu ponto de venda de modo muito particular, levando em consideração, por exemplo, a região onde está inserida e o segmento de mercado a que atende. Dessa forma, o parceiro precisa fazer compras complementares para garantir o mix de produtos de seu ponto venda. Essa é uma situação positiva, pois permite que a empresa mantenha e expanda seus contatos com fornecedores para que, na eventualidade de a aliança ser encerrada, o parceiro não se encontre desinformado em relação ao mercado.

A figura 3 ilustra a atuação da CC no canal de marketing, ligando varejistas tanto a atacadistas como a fabricantes. Comparada com a venda tradicional do atacadista para o varejista, a presença da CC no canal de marketing centraliza os contatos, reduzindo a complexidade e forçando os agentes a se reposicionarem.
Figura 3: Complexidade do canal
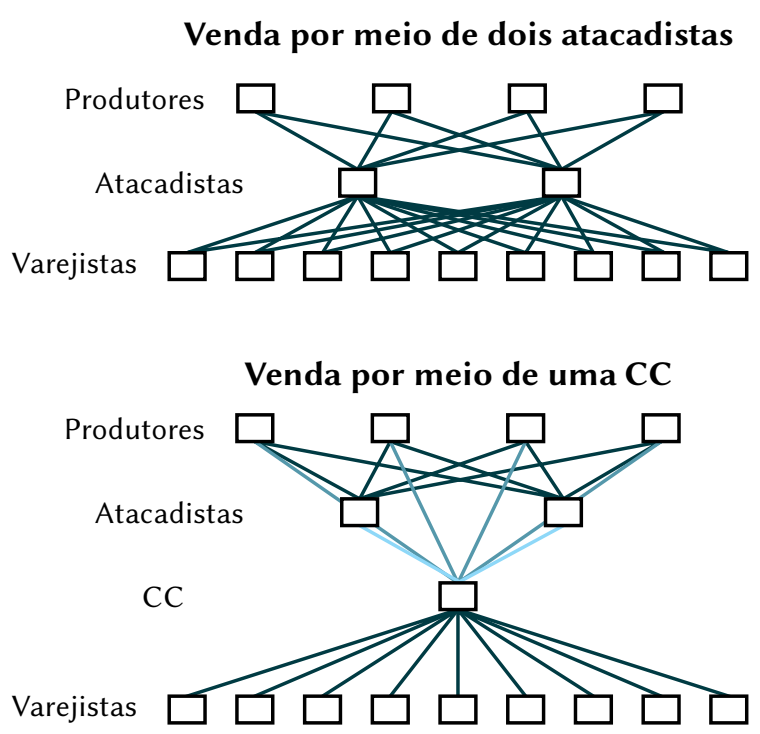

Fonte: Coughlan et al. (2012, p. 23)

A CC, então, passa a influenciar os membros do canal de marketing, o que pode ser entendido como uma característica de poder (COUGHLAN et al., 2012). O poder é recorrentemente visto como uma variável negativa e opressora, contudo pode operar como regulador das forças, tornando mais igualitárias as condições de atuação, a divisão dos resultados e a prospecção de oportunidades. A CC pode utilizar o poder que lhe é conferido para aumentar a coesão das ações voltadas à satisfação dos clientes, direcionando esforços no desenvolvimento de produtos e serviços, de tecnologias, de assistência técnica e resolução de problemas. Em decorrência da atuação da CC no canal de marketing, podem ocorrer conflitos com atacadistas, que entendam que o seu espaço está sendo invadido. Outros varejistas também podem ficar incomodados com o desempenho das CCs, por estas tornarem as condições de competição mais acirradas entre as empresas do setor. Entre atacadistas e fabricantes podem ocorrer desentendimentos em decorrência de privilégios quevenham a ser concedidos às $\mathrm{CC}$. 
Esses conflitos podem ser funcionais para os agentes, impulsionando-os a se aperfeiçoarem e a inovarem, o que é positivo para o canal de marketing que passa a ter um padrão mais alto de eficiência, o que beneficia todos os envolvidos. Contudo, se rumarem para um lado disfuncional, podem causar o enfraquecimento e,com isso, perda da excelência em distribuição.

\section{CONCLUSÃO}

O mercado do varejo, tradicionalmente,é orientado pelo canal de marketing convencional, ou seja, formado pelos fabricantes atacadistas e pelos varejistas. De acordo com esse modelo cada um dos segmentos atua como uma empresa independente, buscando maximizar seus rendimentos mesmo que resulte na redução dos ganhos do sistema como um todo. Devido à intensa concorrência, tanto com empresas nacionais como internacionais, a postura organizacional tem mudado e, com isso, têm aumentado os projetos de cooperação entre empresas do mesmo nível e de níveis diferentes.

As CCs vão ao encontro desta tendência, pois trata-se de um projeto associativo que busca, por meio de compras conjuntas, escala para negociar melhores condições de preço, prazo de pagamento e de entrega. Essas vantagens são repassadas aos consumidores aumentando a competitividade das empresas envolvidas, assim como do próprio canal de marketing.

\footnotetext{
A ocorrência deste tipo de empreendimento tem mudado a configuração do canal de marketing, provocando deslocamentos de poder e redefinindo o papel dos agentes. Com as CCs, os pequenos varejistas passam a ter maior poder para negociar com atacadistas e até diretamente com fabricantes, que podem perceber aí um novo mercado a ser desenvolvido.
}

Dos conflitos gerados por essa nova conjuntura, vem surgindo novas práticas de negociação,bem como todo o composto de marketing é afetado, o que será sentido pelo consumidor em termos de preço, promoções, pontos de distribuição e até da qualidade e especificidade de produtos. Bem geridas, as mudanças e os conflitos são instigadores do desenvolvimento, porém, mal geridas, podem levar à desordem nas relações comerciais, queda na qualidade dos serviços prestados, na rentabilidade dos agentes e na satisfação do consumidor.

Este trabalho, de caráter preliminar, teve a intenção de chamar a atenção para a presença das CCs no canal de marketing. Necessita ainda de verificação empírica, que expanda a reflexão e consolide os conhecimentos adquiridos, ficando essa possibilidade como proposta para trabalhos futuros.

Em um trabalho empírico,pode-se buscar ainda respostas para questões como: os relacionamentos no canal foram afetados pela presença de uma CC? A eficiência do canal sofreu alteração após a entrada de uma CC? A atuação da CC no canal atinge o consumidor final de que forma? Como a CC tem se posicionado frente aos outros agentes do canal? 


\section{MARKETING \\ CHANNEL \\ CONFIGURED \\ FOR PURCHASING CENTERS}

ABSTRACT

The retail sector has constituted Purchasing Centres (Centrais de Compra, CCs) with the intention of getting bettertrading conditions. This is an associative format, which seeks to position itself in the marketing channel between retailers and wholesalers or manufacturers. Created with the aim of increasing the competitiveness of ourpartnercompanies, CCs provide retailers withrepresentation in the marketing channel ahead of the other agents. Thus, the assumption of this study is that the CCs are promoting changes in the relationships of agents that comprise the marketing channel. Through a literaturereview, thispaperseeks to reflect on the presence of CC in the marketing channel, identified as a new agent that will integrate and influence its performance.

KeYwords: Marketing Channel. Retail. Purchasing Centres.

\section{REFERÊNCIAS}

BERMAN, B. Marketing Channels. John Willey \& Sons, 1996, p. 663.

CASTRO, M. R.; LADEIRA, M. B. Práticas colaborativas na cadeia de suprimentos e o papel das novas tecnologias de informação. E-Tech: Tecnologias para Competitividade Industrial, Florianópolis, v. 5, n. 1, p. 32-55, 2012.

CLOSS, D. J.; BOWERSOX, D. J. Logística empresarial: o processo de integração na cadeia de suprimento. São Paulo: Atlas, 2004, 600p.

COUGHLAN, A. T; ANDERSON, E.; STERN, L. W.; EL-ANSARY, A. L. Canais de marketing. 7. ed. São Paulo: Pearson, 2012, 480p.

IACOBUCCI, D. Os desafios do marketing: aprendendo com os mestres da Kellogg Graduate School of Management. São Paulo: Futura, 2001.

KOTLER, P.; KELLER, K. L. Administração de marketing. 14. ed. São Paulo: Prentice Hall, 2012. p. 794.

LAS CASAS, A. L. Administração de marketing. São Paulo: Atlas, 2006. 528p

LEWIS, E. H. Marketing Channels: Structure and Strategy. New York: McGraw-Hill, 1968, 174p.

LOPES, F.F.; NEVES, M. F.; CÔNSOLI, M. A.; MARCHETTO, R. M. Estratégias de rede de empresas: o associativismo no pequeno varejo alimentar. In: V I I S E M E A D, 2005, São Paulo. Anais. São Paulo, 2005.

OLIVEIRA, A. L.; ANTONIALLI, L. M. Redes de cooperação entre pequenas empresas: estudo de caso no setor de supermercados. In: X SEMEAD, 2007, São Paulo. Anais. São Paulo, 2007.

OLIVEIRA, A. L.; REZENDE, D. C.; CARVALHO, C. C. Redes Interorganizacionais Horizontais Vistas como Sistemas Adaptativos Complexos Coevolutivos: o Caso de uma Rede de Supermercados. RAC, Curitiba, v. 15, n. 1, art. 4, pp. 67-83, Jan./Fev. 2011.

OLIVEIRA, S. L.; OLIVEIRA, J. L. R. Os canais de marketing da Eli Lilly do Brasil: uma análise do setor farmacêutico. In: V I I S E M E A D, 2005, São Paulo. Anais. São Paulo, 2005.

PARENTE, J. Varejo no Brasil. São Paulo: Atlas, 2000, p. 400. 


\section{SOBRE OS AUTORES}

PIGATTO, G. Avaliação de relacionamentos no canal de distribuição de mercearia básica. 2006, 230p. Tese (Doutorado em Administração). Universidade Federal de São Carlos. São Carlos/SP.

QUENTAL, C. M.; SILVA, G. F.; LEITE, J. S. Canais De Distribuição: associação de pequenos varejistas. Cadernos Discentes COPPEAD, Rio de Janeiro, n. 10, p. 5-27, 2001.

ROSENBLOOM, B. Canais de marketing e distribuição. In: CZINKOTA, M. R. Marketing: as melhores práticas. Porto Alegre: Bookman, 2001, p. 560.

VOX POPULI. Apresenta informações sobre a pesquisa: Fatores Condicionantes e Taxa de Mortalidade das MPE, 2005. Disponível em: <http://201.2.114.147/bds/BDS. nsf/69C58A809DEF79F832573460064EBF4/\$File/ NT00036036.pdf>. Acesso em: 10 dez. 2007..

Data de recebimento: 06/08/13

Data de aprovação: 20/11/14

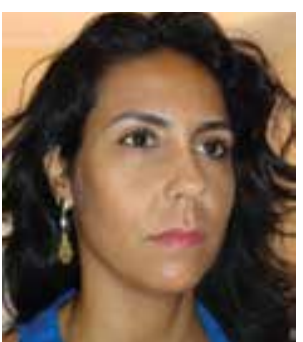

Aline Lourenço de Oliveira

Doutora e mestre em Administração pela Universidade Federal de Lavras (UFLA), especialista em Gestão de Micro e Pequenas Empresas e bacharel em Administração pela Universidade Federal de São João del Rei(UFSJ).Atualmente é professora na Universidade Federal de Alfenas (UNIFAL-MG), campus Varginha. Os principais temas de interesse de pesquisa são: Ensino e Pesquisa em Administração, Teoria das Organizações, Administração Pública, Redes Organizacionais e Teoria da Complexidade.

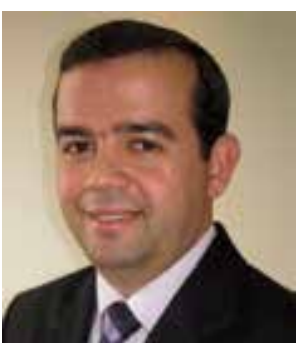

Cleber Carvalho de Castro

Doutor em Agronegócios pela Universidade Federal do Rio Grande do Sul(UFRGS), mestre em Administração pela UFRGS e bacharel em Administração pela Universidade Federal de Lavras (UFLA). Foi coordenador do Programa de Pós-Graduação em Administração da Universidade Federal de Lavras (PPGA/UFLA), Pró-Reitor Adjunto de PósGraduação e Coordenador de Projetos do Centro de Educaçãoa Distância (CEAD/UFLA).Atuou como professor na Unisinos, Unioeste, Univel, Unipar e Unifoz.Atualmenteé professorAssociadodaUFLA, líder do Grupo de Estudos em Redes, Estratégia e Inovação (GEREI), orientador de Mestrado e Doutorado em Administração, Coordenador Institucional da Universidade Aberta do Brasil (UAB) e consultor adhoc para Avaliação Institucional e de Cursos Superiores do Ministério da Educação. 